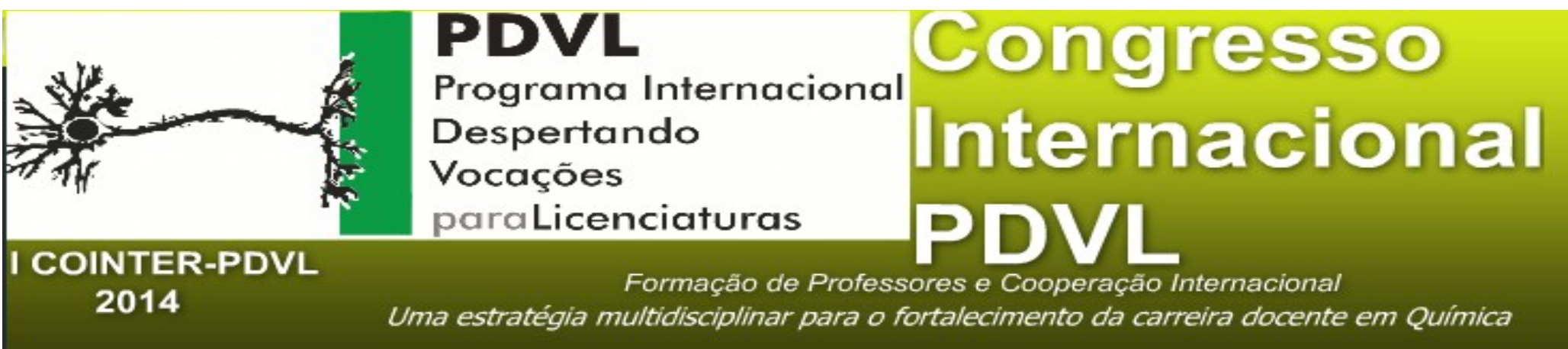

\title{
STOP MOTION: UMA FERRAMENTA LÚDICA NO PROCESSO DE AVALIAÇÃO DO ENSINO DAS LIGAÇÕES QUÍMICAS
}

\author{
Apresentação: Pôster \\ Nairy Rodrigues de Oliveira; Adriana dos Santos Carvalho²; Quêmele Braga de Amorim Almeida; \\ Drielly Campos da Silva ${ }^{4}$
}

\section{Introdução}

A educação tem passado por vários momentos distintos com relação a sua forma de aprendizagem e avaliação. O sistema de ensino em sua transmissão e apropriação do conhecimento tem ocasionado grande preocupação, isso se torna bastante claro, dada a importância que a educação possui no desenvolvimento, caracterização e compreensão da sociedade.

A disciplina de química por ter conteúdos complexos necessita de métodos alternativos e lúdicos durante processo de ensino-aprendizado. E diante das dificuldades que são encontradas por

1 Licenciatura em Química/ Instituto Federal de Educação, Ciência e Tecnologia do Acre/ PIBID-

CAPES/nairyrodrigueso@gmail.com

2 Licenciatura em Química/ Instituto Federal de Educação, Ciência e Tecnologia do Acre/ PIBID-

CAPES/i_ane_carvalho@hotmail.com

3 Licenciatura em Química/ Instituto Federal de Educação, Ciência e Tecnologia do Acre/ PIBID-

CAPES/quemeleamorim@hotmail.com4 Especialista em Metodologia no Ensino de Biologia e Química/ Graduada em Licenciatura em Química/ Instituto Federal de Educação, Ciência e Tecnologia do Acre/ PIBID-

CAPES/drielly.silva@ifac.edu.br 
professores atualmente, têm-se procurado metodologias alternativas que despertem o interesse do discente em compreender a sociedade em que vive, participando, inovando e transformando-a.

O desafio da educação têm sido além de despertar o interesse do aluno para o conhecimento científico, compreender de que forma é possível avaliar o aprendizado, considerando as diversidades e especificidades do educando. As metodologias tradicionais de avaliação têm sido questionada quanto ao seu real objetivo, pois em muitos casos elas analisam a capacidade de memorização de conteúdo muito mais que a compreensão em si.

A utilização do lúdico no sistema de ensino-aprendizagem pode ser um grande aliado no processo de obtenção do conhecimento, pois essa ferramenta proporciona um ambiente agradável para o aprendizado, propiciando a interação do aluno com a ciência através da arte. A técnica stop motion se mostra como uma metodologia facilitadora para esse processo, considerando que o aluno estará envolvido de forma participativa na construção do conhecimento.

O presente trabalho propõe a avaliação do ensino das ligações químicas no ensino médio através da técnica stop motion.

\section{Fundamentação Teórica}

A Lei de Diretrizes e Bases da Educação (LDB n 9394/96) aponta no art.36, seção II, que o currículo adotará metodologias de ensino e de avaliação que estimulem a iniciativa dos estudantes. Além disso, no art. 24, ela afirma que a verificação do rendimento escolar observará alguns critérios, dentre eles, a avaliação contínua e cumulativa do desempenho do aluno, com prevalência dos aspectos qualitativos sobre os quantitativos e dos resultados ao longo do período sobre os de eventuais provas finais.

Acredita-se que a utilização da técnica do stop motion como forma de avaliação pode fazer com que o aluno assimile os conteúdo trabalhados na disciplina de química e demonstre na prática o que aprendeu produzindo um vídeo onde mostre claramente as ligações químicas e como elas se formam. Luckesi (2011, p. 45) afirma que “a avaliação subsidia decisões a respeito da aprendizagem dos educandos, tendo em vista garantir a qualidade do resultado que estamos construindo”.

A proposta de avaliar os alunos com a técnica, permite que eles tenham, na avaliação, mais um momento de aprendizagem, onde vão expressar o que realmente dominam. O que diferencia esta técnica é, o posicionamento do aluno frente ao processo educativo, demonstrando seus valores e 
habilidades, despertando-os para o desejo de aprender. Isto é relevante pois, alguns professores acreditam que o aluno que deveria ter interesse em estudar, mas a necessidade de despertar esta motivação parte também das atribuições do educador. (VASCONCELLOS, 2010)

Segundo Barcelos (2009) “a técnica de filmagem em stop motion, pode ser trabalhada com várias mídias e tecnologias englobando várias disciplinas e conteúdo dentro da Escola”.

O STOP MOTION é que uma técnica de animação na qual o animador trabalha fotografando objetos, fotograma por fotograma, em outras palavras quadro a quadro. Entre um fotograma e outro, o animador muda a posição do objeto, da forma mais minuciosa possível. Para que o filme nos de a ilusão de que o objeto está se movimento, deve-se projetar a animação a 24 fotogramas por segundo, normalmente é utilizado profissionalmente, contudo, a animação nos remete a resultados satisfatórios quando projetada de 12 a 15 fotogramas por segundo (KAMINSKI, 2010).

De acordo com Cunha (2012) a utilização de um jogo didático de química tem como finalidade proporcionar o conhecimento amplo e desenvolver no estudante a capacidade de entender os conceitos químicos e aplicá-los em contextos específicos.

\section{Metodologia}

A aplicação desta técnica foi inicialmente para diagnosticar o processo de aprendizagem de 35 alunos na Disciplina de Química do curso Técnico Integrado de Biotecnologia do Instituto Federal de Educação Ciência e Tecnologia do Acre, no campus Xapuri.

Inicialmente, os alunos foram separados em grupos de 5 integrantes e instruídos sobre a técnica stop motion. Foram orientados a demonstrar as ligações iônicas e covalentes, utilizando a criatividade para demonstrar através de imagens como ocorrem as ligações químicas. As imagens foram montadas com desenhos, pinturas e recortes e, estas foram colocadas em uma cartolina branca, fotografando cada movimento.

Em seguida, através de softwares específicos para edição de imagens, eles finalizaram o trabalho adicionando efeitos sonoros e visuais. Cada grupo apresentou o trabalho realizado ao restante da turma, sendo avaliados pelo docente da classe com base no envolvimento dos alunos na atividade e no desenvolvimento cognitivo expressado na atividade.

\section{Resultados e Discussões}

Segundo Kaminski (2010) “O stop motion é uma técnica cinematográfica, simples, 
de baixo custo, e nos remete a resultados muito satisfatórios tanto em questão de aprendizagem dos alunos ao tema sugerido, quanto ao interesse dos mesmos na produção de sua própria animação”.

Essa técnica se mostrou eficaz aplicada no contexto desse trabalho, onde observou-se nos discentes total envolvimento e participação na atividade em todas as etapas (Figura 1). O conteúdo de ligações químicas foi abordado de forma efetiva no material confeccionado e, de maneira divertida e prazerosa os alunos prepararam e assistiram as apresentações dos grupos. De acordo com Silveira (2008), para gerar no estudante a necessidade em transcender a informação e mergulhar na busca do conhecimento, pode-se utilizar o conhecimento “científico” dentro dos limites da ciência ou expressando sentimentos e sensações sobre a ciência por meio do imaginário e da arte.

A avaliação dos alunos através dos vídeos produzidos, observando a criatividade de introduzir os assuntos trabalhados em um método alternativo, de maneira relevante estimula os discentes que não se identificam com a disciplina de química, muitas vezes devido aos métodos tradicionais, a se empenharem em atividades que tenham afinidades e conhecimento.

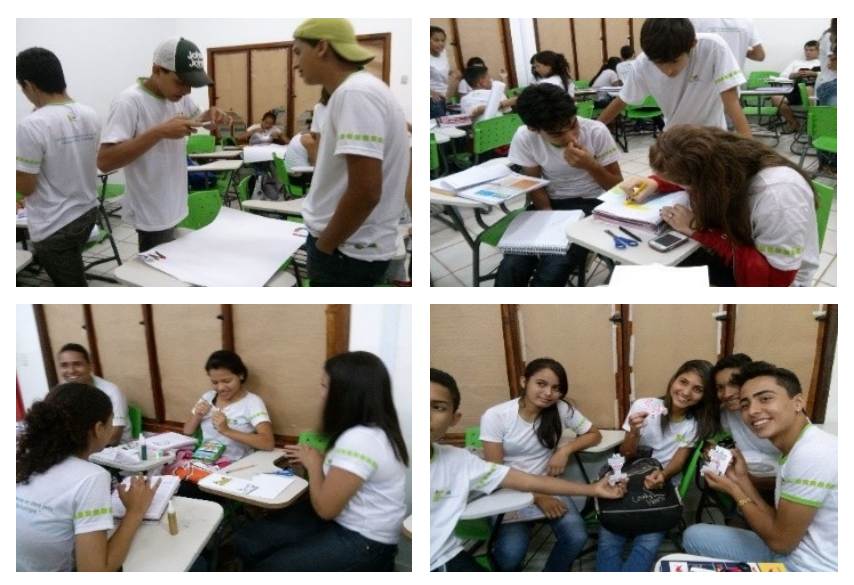

Figura 1: Confecção do stop motion

Essa forma de avaliação descaracteriza a metodologia tradicional em que o aluno é analisado principalmente por sua capacidade de memorização através de provas. Atualmente o 
docente deve estar preocupado e disposto a avaliar seu trabalho em uma perspectiva mais inclusiva, tanto no que se refere a sua prática metodológica quanto na forma como avalia seus alunos.

\section{Conclusões}

Considerando os resultados positivos alcançados na atividade proposta, no qual foi possível observar maior aprendizado e desempenho escolar, conclui-se que o objetivo foi alcançado. O stop motion demonstrou-se uma técnica complementar e facilitadora para auxiliar o professor de química em sua conduta na sala de aula, podendo utilizar este recurso metodológico no conteúdo de ligações químicas, assim como, em outros conteúdos.

Este trabalho trouxe para o grupo de pesquisa uma visão diferenciada da prática docente, contribuindo para a descaracterização do modelo tradicional de ensino, aprimorado através de metodologias alternativas, servindo de suporte para as experiências educacionais futuras.

\section{Referências}

BARCELOS, S. F. Cinemática e Óptica: utilizando conceitos básicos na animação em stop motion. Ponte Alta do Norte - SC, 2009. Disponível em:< http://nead.riogrande.ifrs.edu.br/midias/pdfs/sandro.pdf>. Acesso em: 17 Out 2014.

BRASIL. Lei $\mathbf{n}^{0}$. 9.394, de 20 de dezembro de 1996. Estabelece as diretrizes e bases de educação nacional. Diário Oficial [da] República Federativa do Brasil, Brasília, DF, 23 dez.1996. Disponível em: <http://www.planalto.gov.br/ccivil-03/LEIS/L 9394. htm>. Acesso em: 27 ago. 2013.

CUNHA, M. B. Jogos no ensino de química: considerações teóricas para sua utilização em sala de aula. Química Nova na Escola, São Paulo, v. 34, n. 2, p. 92-98, Mai 2012.

KAMINSKI, V. R. Animação no ensino fundamental: stop motion. Ponta Grossa, 2010. Disponível em: http://www.fap.pr.gov.br/arquivos/File/extensao/2-ENREFAEB_3-SimposioAV/15ValeriaRaquelKaminski.pdf. Acesso em: 17 Out 2014.

LUCKESI, C.C. Avaliação da aprendizagem escolar: estudos e proposições. São Paulo -22. ed. Cortez, 2011. 
SILVEIRA, M. P. KIOURANES, N. M. M. A música e o Ensino de Química. Química Nova na Escola, n. 28, p.28-31, mai. 2008.

VASCONCELlOS, C. S. Avaliação da Aprendizagem: Práticas de Mudança- por uma práxis transformadora. $11^{\mathrm{a}}$ ed. São Paulo: Libertad, 2010. 